escape where oil had not been applied. From August 10 to 25, during the August perigee, 2.85 inches of rain fell, an amount ample to provide a brood on its own account. At the time of the first September brood it rained in all 0.95 of an inch, enough to materially increase the size of that brood. All in all, rain-fall conditions in 1912 decidedly favored an abundance of salt marsh mosquitoes about New Haven.

Investigations along the line of the relations of the tides and rainfall to breeding of salt marsh mosquitoes are far from complete, and offer an interesting opportunity for the investigator looking for a chance to increase our knowledge of the obscure physical causes which influence the varying abundance of life on our planet. Such an investigation would in the end pass out of the field of the entomologist into that of the engineer, or physiographer and the geologist, according as stress was laid on the tides or the marshes, but there is room for much more investigation on the purely entomological side.

\title{
NOTE ON THE FLOWERING AND FRUITBEARING OF YUCCA ALOIFOLIA IN SOUTH AUSTRALIA
}

By J. G. O. Tepper, Norwood, South Australia

Twenty years ago the writer contributed a short note to Insect Life, 1892 (Vol. IV, p. 74), when he first observed sound, but then still immature fruit at a distance from Adelaide of 30 miles; this struck me as singular on account of its dependence upon a highly specialized moth, endemic as well, in the American home. Excess of office work prevented me from investigating the problem personally as to the pollination of the Yucca in this state, there being no plants accessible to me, and the few other South Australian lepidopterologists were probably in a like fix, for nothing so far seems to have been done to discover the insect agent. However, a year or two later I acquired a young shoot of the fruiting species of Yucca, and planted it in my own back garden, where it prospered and grew, but did not flower for many years.

Three years ago, however, when the tree had attained a height over eight feet, it developed its virginal flower spike, but this set no fruit. Last year (1911), however, it produced two opposite branches near the crown, and both of these developed flower spikes, one a month in advance of the other. Of these, while the earlier one was in flower, but still bore buds, and the later only immature buds, I managed to take a photograph (Pl. 8, Fig. 1); December 22, 1911, of the crown with some difficulty. The older spike (right side) remained sterile, although 
some of its late flowers were still open, when the younger one was in full flower a month or so later. The crown of the tree was now about 10 feet above the ground.

Ten fruits were developed by this younger spike and first noticed during February to March of this year (1912) although I am not aware of any other Yucca specimens existing within several hundred yards of mine. The flowers continued for from two to three months, and their shrivelled remains persisted much longer, while the fruits grew extremely slowly, attaining to proximate ripeness during October only. On the 3d of that month a photograph (Pl. 8, Fig. 2) was taken of the top of the tree, and in nearly the same direction as No. 1 (looking south) but from two feet distance with a portrait lens attached to the camera ("Brownie No. 2"), and showing the fruit from the north (i.e., sunny) side. On the 9 th, I cut out both spikes, and photographs were taken showing them from the reverse side (Pl. 8, Fig. 3). Some of the fruits were now soft and overripe, and one cut open a few days later was found too far gone for the detection of insect remains, the soft pulp being purple-veined. This fruit, one of the largest, contained 138 flat, black and perfectly ripe seeds and a much less number of small, thin, white ones, mostly located at and near the stalk end. The size of these varied from under three to over four inches and I remit two as samples for examination by experts ${ }^{1}$ for external marks of insect agency, comparison with American fruits, etc., by separate parcel, and also a few of the peculiarly shaped seeds. These appear to me to resemble tick species in color and form, which may possibly assist in their distribution by birds feeding upon those animal parasites, and which, deceived by color and form, swallow them, and pass them softened with their excrement.

In Professor Riley's response appended to my note in 1892 (Ins. Life, IV , 74) reference is made to certain characteristics of the leaves being required for the determination of the species. The leaves of my tree are 20 to 23 inches long, $\frac{3}{4}$ to over $1 \frac{1}{2}$ inches wide, very rigid and most acutely pointed, the upper side concave and smooth, the margins minutely rough-edged, forming crowded spirals near the crown. The older leaves bend backward and are finally closely adpressed to the trunk and long persistent when dry. The trunk of the tree is now fully six inches in diameter, and the total height, inclusive of the three branches, over ten feet.

Thus far then as my observations go, it took about 16 years in the

'Mr. August Busck, at the request of Dr. Howard, examined the specimens and found no evidence of insects. The specimens were very moldy and further comparisons were impracticable.- $-E d$. 


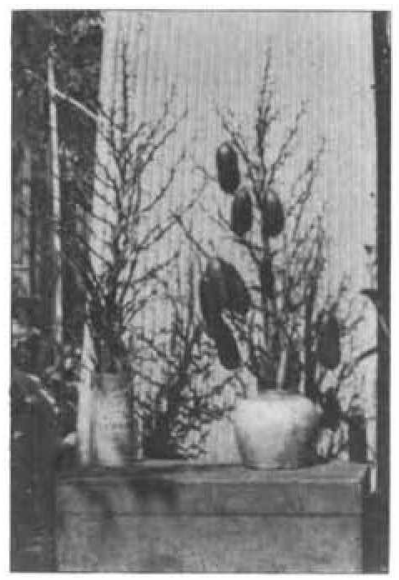

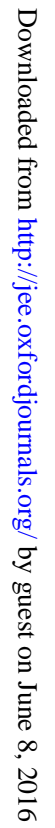
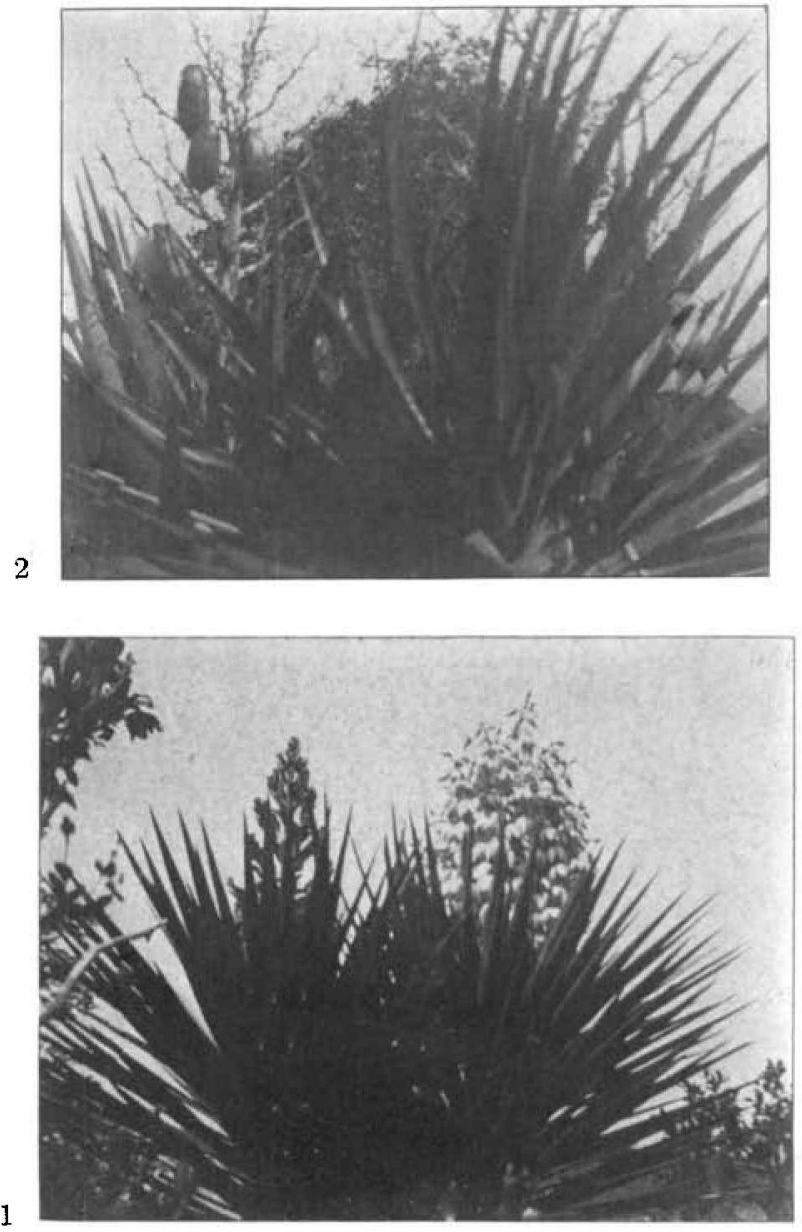

Yucca Flowers and Fruit 
locality before the first flowers were developed, but these without yielding fruit. The floral spike terminating the central axis of growth, two lateral opposite branches developed, but it took two years before the second set of flowers appeared, one spike being a month in advance of the other, and of which the earlier one also remained sterile while the later one produced a small number of fruits, that is, became pollenized by some agent adapted for that purpose, during January or February, the hottest summer months in South Australia. To complete the cycle of budding, flowering, fruit-setting and ripening it required about a full year, and likewise the cycle of the metamorphosis of the fertilizing insect from the egg, through the larval and (probably) pupal stages, passed within the slow growing fruits. Considering the absolute interdependence of plant and insect, the fruiting here, so far from their endemic home is very remarkable in this case, and appears to be explicable in two ways only, both equally problematical. The first is that Pronuba yuccasella larvæ were introduced with or imported with Yucca fruit to an Australian locality, where flowering Yucca trees existed when the imagines emerged from the pupal shell, in or near the fruits in which the eggs and larvæ developed.

The second alternative is, that an Australian insect exists possessing similar organs, viz., prehensile maxillary appendages and long, extensible boring ovipositor, as the Pronuba, which has yet to be proved. I have not yet come across any evidence that either of the above alternatives has been investigated, and probably no person even lives now that could assist in proving the introduction theory.

\section{EXPLANATION OF PLATE 8}

1. Yucca aloifolia budding and flowering spikes, looking south, south west.

2. Ripe fruits, trunk 10 feet high, looking south.

3. Sterile and fruiting spikes, detached and shown from the reverse side as seen in figure 2.

\section{FALL ARMY WORM}

Laphygma frugiperda (S. \& A.)

By J. A. Dew, Field Entomologist, Auburn, Ala.

The purpose of this paper is to set forth the facts in regard to the fall army worm which were determined during the outbreak last year. Owing to the fact that previously there has been little investigation concerning this species and because the worms are present in local areas again this year, it was thought best to give in condensed 